\title{
THE STUDY OF MAERIAL CULTURE FOR ART LEARNING AND MAKING: AN ONGOING JOURNEY WITH A/R/TOGRAPHY
}

\section{Peisen DING *}

Department of Curriculum and Pedagogy, Faculty of Education, University of British Columbia, Canada

\begin{abstract}
Art making has its uniqueness that not only involves visual language expressions and interpretations but also offers both art creators and the audience aesthetic, multi-sensory and embodied experience. It is affective and can contribute to cognitive development in the way of being affective (Addison, 2011). In art lessons, students can learn by doing which means there is no absolute order between learning and doing or isolation between affective experience and cognitive knowledge. Moreover, "by focusing on affect, an energy rather than a representation, the artist (or the student) engages with both the most extreme, and, more particularly, the minutest fluctuations in the intensities of their experience" (Addison, 2011, p.369). For the development of students, a/r/tography can be a great methodology to explore these "extreme and minute fluctuations" in art learning, and consequently to help students get into a zone to explore the unknown and potentiality art making in relation to their living experiences. This paper will mainly discuss how a/r/tography can be a methodology to be applied in art learning and making for primary school art lessons by theoretical investigations of case studies. Moreover, as a/r/tography has power to help students 1) create their own artworks and visual language to express their learning experiences, 2) establishing living inquiries to experience their lives deeply and effectively, and 3) encouraging both self-learning and peer-learning modes, this paper will also convey opening assumptions for curriculum design in art education.

Keywords

Maerial Culture, Art Learning, A/R/Tography, Multi-Sensory, Cognitive Knowledge.
\end{abstract}

\section{Introduction}

A/r/tography is a practice-based research methodology, occupying the characteristics of "rhizome" which is an assemblage rather than an isolated unit, and is also dynamic with its own agency (Irwin et al., 2008; Irwin \& Springgay, 2008). Subsequently, it has meaning and power that can fold and unfold "art making, researching, teaching and learning in and through practice, and in and through time" (LeBlanc \& Irwin, in press), with a correspondence to a fused identity of an artist, researcher and teacher. Furthermore, a/r/tography demands people with this fused identity to consider the space of in-between and the significance of the relationships among subject, object, situation, time and space (Irwin \& Springgay, 2008; LeBlanc \& Irwin, in press). That is because when $\mathrm{a} / \mathrm{r} /$ tographic research is considered as living inquiry it is actually located in an in-between space without standardized instructions and rules (Irwin \& Springgay, 2008; LeBlanc \& Irwin, in press). As a result, a/r/tography has the capabilities to 1) help us explore the agency of environments impacting on our experience, 2) encourage us to use more art forms and languages to express our experience, 3) convey us creative hints obtained from various experience and combinations of surprising moments, 4)

* Corresponding author: edcp.educ@ubc.ca 
invite us to enter a social process and rethink our identities and its relation to others, or the environments that we inhabit during our experience, and 5) require us to rebuild our fragmentary memories to see other possibilities after the experience (Leggo, 2008). As such, $\mathrm{a} / \mathrm{r} /$ tography is creative, innovative, and remarkable. Based on the understanding of $\mathrm{a} / \mathrm{r} /$ tography, this project uses walking as a method, trying to explore more possibilities of the ways to study material culture and more pedagogical potentials for art learning and making during this walking journey from a new materialism perspective. New materialism as Springgay and Truman (2018) mentioned entangles the methodologies of walking and morethan-human modes in qualitative empirical research, which can help us unfold more possibilities. Moreover, by applying the methods of walking, mapping and visual journaling and the methodology of a/r/tography which is a practice-based methodology for aesthetic experience and new knowledge establishment (LeBlanc \& Irwin, in press; Leblanc et al., 2015), the experiment of this project consists of a continuous dialogue that the author stays with the heritage building of Irving, K. Barber Learning Centre at the University of British Columbia for one hour daily, being inspired and offering a series of visual diary to demonstrate the denotation, connotation, metaphor and new understandings of the building in relation to himself and the environments. The reason to choose visual diary as a main presentation is not just due to the letter "a" as an element in a/r/tography. More importantly, it is because sometimes, written language is hard to describe the walking experience. O'Sullivan (2001) states that writing about something is silly. Instead, writing should be considered as a parallel to artworks, emancipating objects from the existing or pre-interpreted contexts. Because writing has the ability of expansiveness which should replace the normal use of writing for the negation of the interpretation of objects and artworks. Moreover, writing as being different from art-making can lead to a new creation. Subsequently, writing itself can be an art, and, along with the artwork, both are coexisting, mutually effected and co- changing. Together, the artwork is becoming richer and richer. This is also the idea of a/r/tography which combine "a/r/t" with "graphy", employing both visual and written languages (Irwin, 2004). Also, this is the way how this paper generated, significantly writing with the images from my visual diary. Moreover, as it is a continuous living inquiry which could be meaningful and creative with more impressive experiences, there will not be an end, and this project is opening for more ongoing ideas from the readers. 


\section{Thinking Material Culture with New Materialism}

The studies of material culture and visual culture have disparate focuses while there do exist connections. On the one hand, art materials as objects belonging to material culture can imply ideas of art making and design possibilities based on our living experience and cultural background; on the other hand, ancient paintings as art pieces are able to demonstrate us not only the techniques and process of art making but also the history behind and indicate the past reality situated in material culture studies. Bolin and Blandy (2003) also state that material culture can supply politic, economic, ethnic, cultural and historical elements for art education and provide students the connections between art practices and their daily lives. This is also the main reason why material culture was brought up to this a/r/tography project. Furthermore, materials have their own power to communicate and interact with the public, and Bennett (2010) calls this power, "thing power" which can expand the understandings of materials and objects and could be applied in aesthetic experience as well. Moreover, each "thing" can be regarded as an assemblage with the invisible internal actants affecting and being affected by each other. Also, each "thing" with its surroundings also can be considered as an assemblage with various tangible and intangible bodies. This "assemblage" idea is also greatly helpful to evoke and invite scholars to think about/with the kinetic energy of objects and more potentials of material culture in relation to human society, during the re/searching experiences. Significantly, the concepts of "thing-power" and "assemblages" suggested by Bennett (2010) have the ability to change the ways that scholars considering material culture, which largely reflect vital materialism and the philosophy from Baruch Spinoza. For "thing-power", things as actors have their own power that can communicate with and impact on us. In terms of "assemblages", firstly, they are affective, vibrating and merging internally and externally. In one assemblage, an "actant" never shifts alone (Bennett, 2010). Subsequently, agency always emerges with collaborative and interactive intervention with diverse bodies and energies. In consequence, human also can be in this assemblage, and interact with it reflecting humannonhuman agency. As Bennett (2010) says, "humanity and nonhumanity have always performed an intricate dance with each other". Secondly, assemblages do not have any central head as each part can balance their power and changing with each other. Lastly, assemblages should be treated as living mechanisms. Efficacy, trajectory and causality are the concepts helping us access to the agency of material culture in this assemblage. Firstly, efficacy is the creativity of agency, stimulating the power to make a difference or something new happens and call for response from different bodies (Bennett, 2010). Trajectory is then closer to a movement from the nonhuman bodies that can be obvious as well as ambiguous or even absent 
but always respond to us in any visible and invisible, tangible and intangible ways. The trajectory can come from the past but more importantly, exists not only in the past but also the present and the future. The last one is causality which has a focus on the process of change that contains expressive agency. To be more specific, it concentrates on different actants or bodies that give their impacts on both the previous and the next level through a movement. It can be knowable while mostly not knowable as the force can be from both internal bodies and external allies. Three of them are all dynamic, proceeding from spatiotemporal configurations and forming new associations in the assemblages toward a different group of allies. Sequentially, the living mechanism of assemblages emerged. Remarkably, this "assemblage" idea is greatly helpful to evoke and invite scholars to think about/with the kinetic energy of objects and more potentials of material culture in relation to human society.

However, in terms of "agency" of objects discussed in "assemblages", Ingold (2013) points out that "animacy" can be more proper for naming the power of objects. Because agency, firstly, is commonly regarded as an embodiment in a closed status. Therefore, sometimes, agency is not an appropriate word to describe the impact of material culture or environments functioning on human choices and behaviours or themselves reactions to each other. Take "the kite in flight" as an example, Ingold (2013) points out that, when people are flying kites, "air is opening itself", which means air or wind is fluid, invisible, changing and elusive, and subsequently, it is against the concept of "embodied agency". Secondly, the idea that humannonhuman agency has the ability to establish interactions among materials, objects, human and environments has been popularized. This is because it is not always accessible to see interactions between merely different objects/materials. Ingold (2013) says, "you do not ... need clay to interact with the wheel, but you do need a wheel to correspond with the clay" (p. 101), when you are making potteries. Significantly, in both cases of pottery-making and kite-flying, human body, materials and environments are mostly corresponding and affecting each other's movement rather than "inter"-acting. Furthermore, for animacy, Ingold (2013) indicates that it is an opening status floating among people, materials and environments. Therefore, "a dance of animacy" is able to wander among different bodies corresponding and affecting each other temporally, spatially and sentiently; and consequently, animacy builds a vivid choreography. It gives us a new insight to turn objects from passive to active existence. Reversibly, Ingold (2013) indicates that separating human beings from materials is problematic and can blind us to see the potentialities as well. Indeed, human beings are things, constructed by countless cells that form organs, bones, veins, etc. By setting people as objects without diminishing their value as subjects, it can also suggest us to consider the intersubjectivity of objects and subjects as 
well as the "entirety" with less boundaries inside the whole mechanism. Moreover, continuing seen individuals as things, in a way, people can be defined as "processes, brought into being through production, embroiled in ongoing social projects, and requiring attentive engagement" (Pollard, 2004, p. 60). Self-objectification, as Steinweg (2011) states, is also one condition for the objectivity of the object its being to be established in the subjectivity in the being of the subject. Consequently, "as for me, I will disappear into the parade of things" (McCollum, 1986, p. 6).

For the Inspirations to my a/r/tography project with these ideas, firstly, it let me reconsider my project object Irving, K. Barber Learning Centre that is neither subject nor object but a "living mode" encompassing an assemblage of various simple bodies. It can be easily observed that there are books, pianos, stairs, tables, chairs, doors, human beings inside Irving, K. Barber Learning Centre. Each body is constructed by different materials with disparate efficacy, trajectory, and the interactions among these bodies demonstrates causality making the building alive. Hence, by jumping out of the existing concept of material culture studies and embracing new materialism, this project anthropomorphizes Irving, K. Barber Learning Centre, which could 1) reflect social and cultural connections with material culture, 2) encourage processes of art making and learning with human- nonhuman animacy, 3) bridge the gap between material culture and visual culture with extraordinary hints to art education, and 4) generate even more potentialities that cannot be predicted. Secondly, as Ingold says that it is important to consider human as things and decentre the human power, I was trying to let my walking experience directed by this assemblage of Irving, K. Barber Learning Centre, enjoying the "lost" feeling of my journey. Somehow, these ways of getting familiar with material culture suggest me to form alliances and enter assemblages, and to change and be changed by other bodies/things. It significantly advises me more ways of aesthetic experience and asks me to consider the effects and affects. Therefore, let us start the journey to unknown space with my visual diary!

\section{Aesthetic and Multi-sensory Experience with Repetitive Visiting}

This a/r/tography project through walking around/in/with Irving, K. Barber Learning Centre consists of four propositions (before the encounter, during the encounter, after the encounter, and Re-encounter). To be more specific, Proposition 1 is for thinking as many as my ideas of Irving, K. Barber Learning Centre before visiting, aiming to 1) making connection with the building and 2) avoiding staying in the thoughts that could blind potential findings in the next stages. Proposition 2 can be regarded as one of the most important parts, including a repetitive process that the author visits the building every day for one hour, walking around and in it to observe, feel, and experience and consequently, let the art happens naturally. Proposition 3 is 
1) to give time for rethinking the "thing power" (Bennett, 2010) and "animacy" (Ingold, 2013) of the building and the mutual relationship among the building, surrounding environments and the author with an aim for future research of Irving, K. Barber Learning Centre, and 2) to process artworks inspired by this repetitive activities. The final propositional invitation is for exploring the unfamiliar familiar and the familiar unfamiliar. All these propositions will firstly be recorded in a visual diary, and then turned to new understandings of material culture and possible and reasonable perspectives to study material culture along with pedagogical meanings.

\section{Before the Encounter}

At September 15th, the first day, I started my journey with Irving, K. Barber Learning Centre. One of the reasons that I selected Irving, K. Barber Learning Centre which is a heritage building as my study object is because of my educational background containing Fine Arts, Art Education, Experimental Archaeology and Material Culture Studies. However, I was also wondering what the other reasons can be. Consequently, the first interesting question in my mind is how and why this building have attracted me, apart from the reason of my educational background. The answers may locate in my potential awareness that eagers to know the mystery of its past, to realize my desire of studying, and to appreciate the charm of its design. It seems that all these thoughts are from myself, however, may I quest whether these thoughts are intentionally hinted to me by Irving, K. Barber Learning Centre as its existence demonstrates the great history of the building, the function as a library, the novelty architecture design combining both heritage and modern structure? Sequentially, may I keep questing whether these elements of this building are related to the activities between the past society and Irving, K. Barber Learning Centre, and the situation of the natural environment and the availability of raw materials that past architects had to considered and applied to their design? Somehow, these questions and quests explained that human and nonhuman animacies are actually interacting and influencing each other in the continuous time line and meaningchanging space.

With the new ideas of human-nonhuman animacy, I was trying to anthropomorphize Irving, K. Barber Learning Centre, attempting to explore the consciousness of material culture. Sequentially, many questions coming to my mind that I would like to question Irving, K. Barber Learning Centre before I visited it, such as:

How did you have your name? When were you born?

Who designed and created you?

Do you like art or you prefer design which give you a new appearance combining two modern 
wings?

What and who you are living with? Do you have any family members? What's your life goals? How you express yourself and communicate with people?

What's your favourite part of this campus? What's your most proud part of yourself?

What's the relationship between you and the clock tower in front of you?

Figure 1 illustrates the investigation of and play with the fonts established in 1925 when Irving, K. Barber Learning Centre was built around the refurbished core of the 1925 UBC Main Library, aiming to explore more connections between the present and the past, and more potential relations with the library outside the context. Figure 2 demonstrates not only these questions, but more importantly, my mind which is indicated through chaotic lines on the paper. They all represent my nervous, confused, and excited feelings of unknown. The lines using pink, purple, red and orange which are all warm colors also show my positive, passionate and activated emotion. As this process is subjective, one interesting standpoint from this proposition is that we ought not to expect current scholars from different humanity disciplines and people from the past to think or behave in the same ways as we might when we study material culture. Otherwise, it could limit our learning lens and our understandings of material culture. Hence, when studying material culture, it is important to be opening to broader aspects, contexts, and bodies. The following walking experiences will deliver how "broader" the studies of material culture can be. However, there could be always more potentials that we cannot see. Certainly, this paper will not cover everything as well. As the spelling of "cover", once we try to cover everything, it is "over" actually. Consequently, the research is dead. The significance of $\mathrm{a} / \mathrm{r} /$ tography is asking us to keep inquiring and finding meanings during our experience. It is always ongoing, and that is why it can be full of potentialities. 


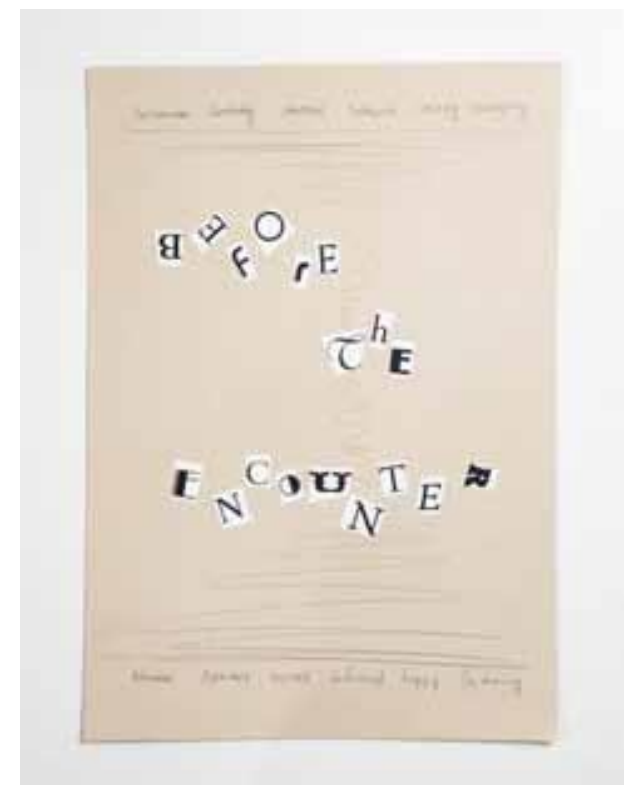

Figure 1- The start page

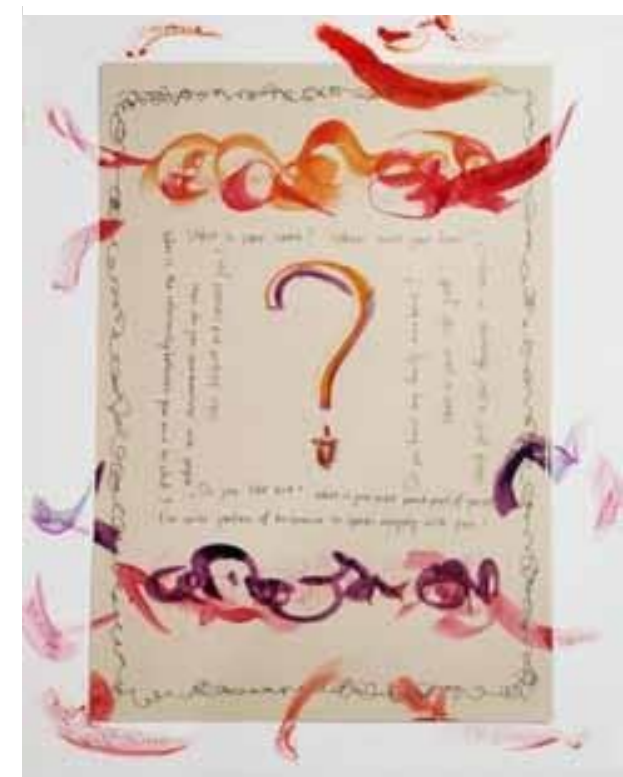

Figure 2- My mood before the encounter

\section{During the Encounter}

I- Smelling the Nature Outside the Building

Sunshine, lawn, fresh air, What a cozy atmosphere.

However, life won't be always smooth here.

What have you experienced? What have you expressed? 


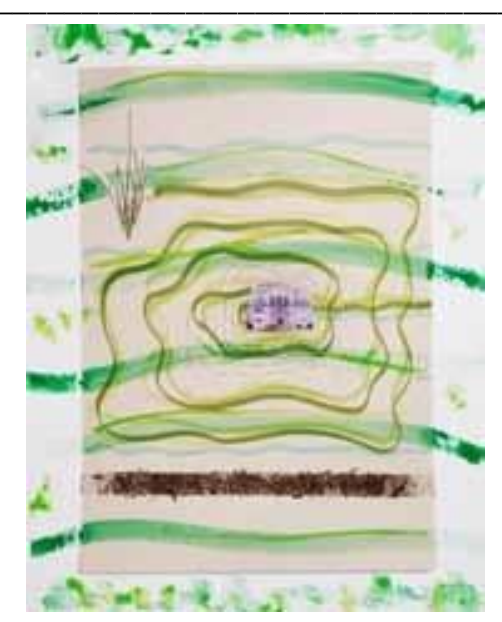

Figure 3- Smelling the natureoutside the building

II - Listening the Clock Outside the Building

Clock tower bell sound never stops; Every single hour you have to be woken up, Like every daily routine we have to follow.

How can we resist? How can we break?

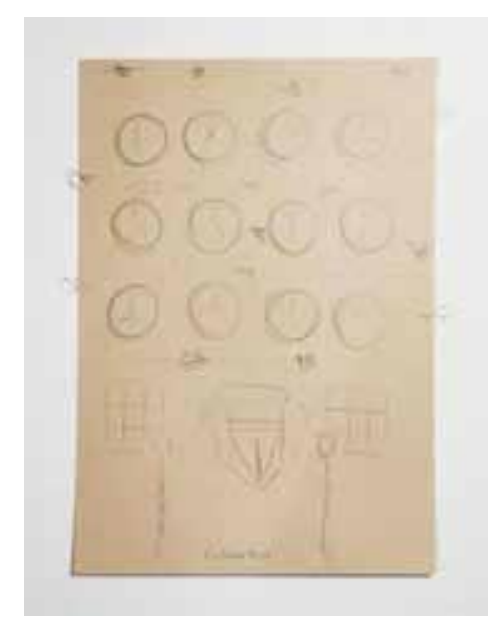

Figure 4- Listening the clock outsidethe building

III - Observing the Interactions among the Environment, People and the Building Human beings left trace on your body; You cannot scream but do react.

But sometimes, we are just too ignorant.

Why people merely speak for vulnerable materials? Why people hardly realize the changing nature? 


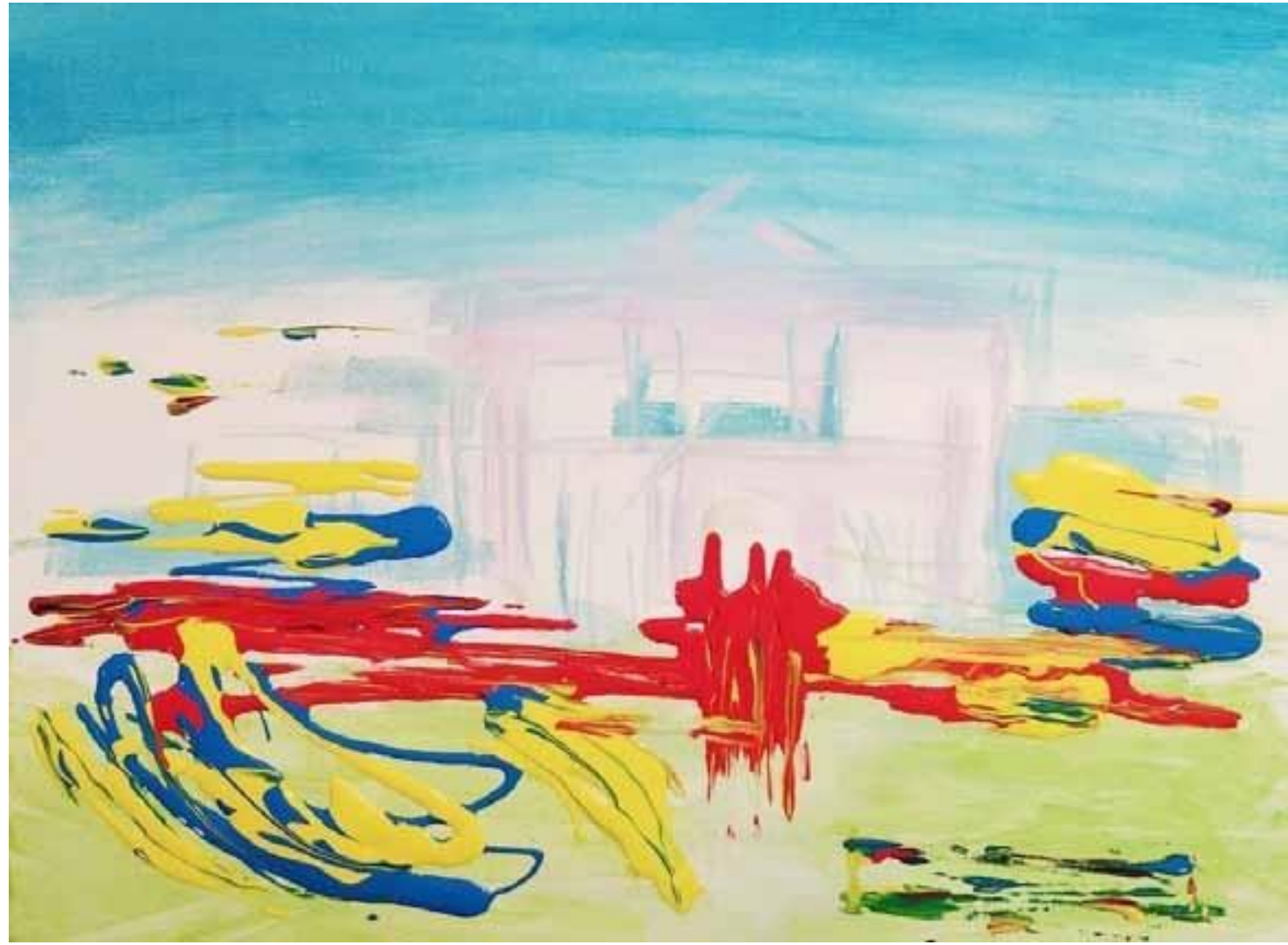

Figure 5- Observing the interactions among the environment, people and the building

I started my walking around and outside the library to feel the environments and the building. It requires me to think about natural environment as an important factor should be considered in material culture studies. It also connects the selection of raw building materials and the sustainable considerations of library and its surroundings with the processes of architectural design. However, ironically, people sometimes ignored the existence of the learning centre, and the studies of material culture also more focus on human movement. It could be crucial for scholars to re/consider "thing power" during their studies of material culture as well, such as the capabilities of different materials and the correspondence of the building to human activities. Consequently, I painted Figure 5.

IV- Walking into You

Heavy rain, Strong wind, and mystery history of you, Push me waking "into" you. Yes, You are a library;

But you are also a warm and imaginative space, Connecting the past, present and future. 


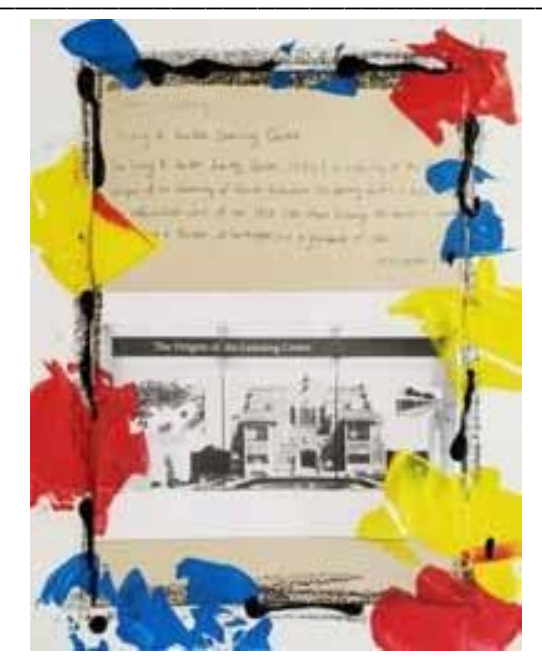

Figure 6- Walking into You

Clark (2011) says, "history is the study of the past, (and) the past is not history". It strongly reveals that the past is not just one history and there are many things that we do not know about it. History is constructed by historians fragmentarily through only the remained evidence of the past, and it cannot be the same and even sometimes it is not true. Maybe, it is better to consider histories as stories. We should not absolutely believe in history interpreted by others, as there is always a "lie" in "believe". However, if we cannot absolutely believe in history, how should we study the past and how should we consider material culture? My visual diary for Day 5 walking experience may be able to convey some parts of the answers. Firstly, I walked into the second floor, seeing the history of Irving, K. Barber Learning Centre displayed on a glass board. But I was doubting whether it is everything of the learning centre. To be critical, it is not. I see Irving, K. Barber Learning Centre alive, actively corresponding to the construction by human. It got two more wings; it became moderner; it shows human desire of colonization; and it has been changing, simultaneously asking people to care about his conditions. Therefore, I used black to outline the learning centre, but not completely close. It got interrupted by primary colours. The reasons are 1) black and white cannot represent everything or divide everything, and 2) primary colours can be a metaphor representing main history of this learning centre interpreted by historians, but there are always other possibilities and that's the reason why secondary colours come up and people can create different colours by mixing primary colours. Hence, when studying material culture, it could be more important to study the relationships among objects, people and ourselves, instead of fully relying on the history.

V - Touching Your Body

I was wondering what raw materials were utilized to build you,

Thus, I start to get "into" you. 
I try to memorize my aesthetic experience by touching; I also try to record my feeling in art forms,

However, it is beyond written language as well as hard to capture in visual language. Hence, I am still on my way and let time answers me.

I $\quad$ - Recording My Walking Patterns

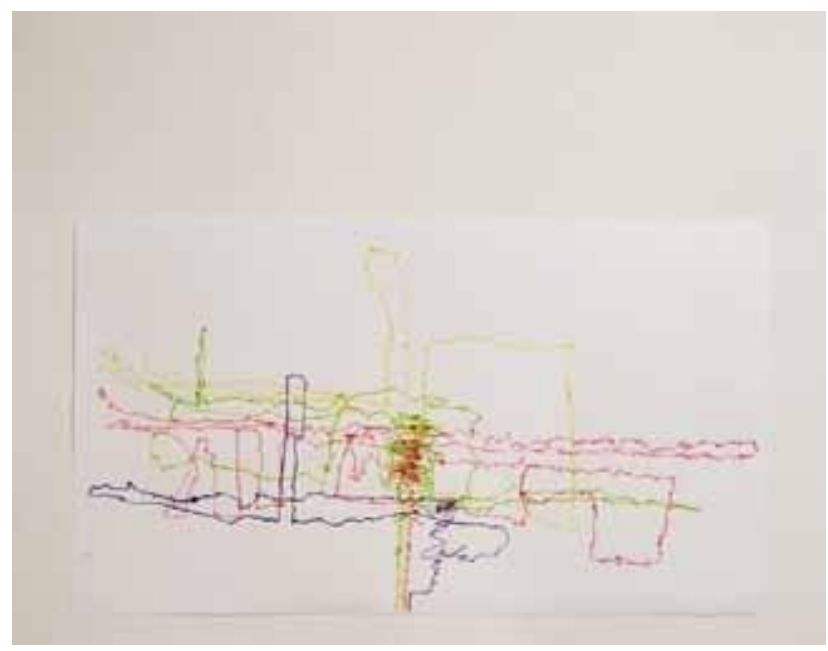

Figure 7- Walking pattern inside the building

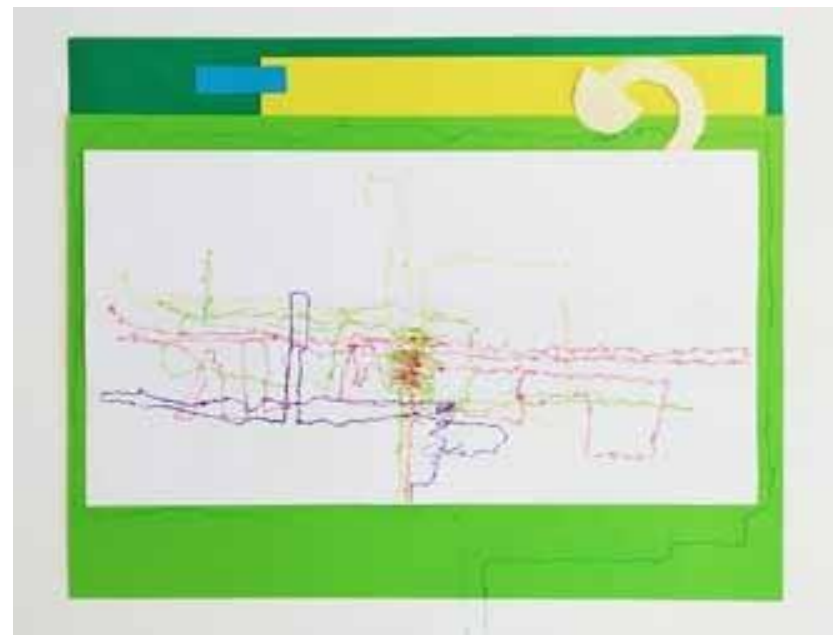

Figure 8- Walking pattern inside and outside the building

I walked into the library to observe and draw the floor plan of each floor each day. It cannot be denied that it is a confusing design, because the first floor is the floor underground instead of the entrance floor. For the entrance floor, it named the second floor. Consequently, I was thinking if I introduce to a person who never been to this library that he/she need mainly enter the library through the gates of second floor, would this person think he need to fly or climb to the library? Hence, sometimes, it is necessary to study material culture critically and should not be blinded by its beautiful appearance. 
Afterwards, I walked into the learning centre again and meanwhile was recording my walking patterns on four floors respectively with purple (for the first floor as it is underground and quieter), green (for the second floor as it is the entrance floor which more close to the green garden), red (for the third floor as it is an intense area that most people choose to study here) and yellow (for the fourth floor as it is the top floor where is closer to the sun). As Figure 7 shows, I drew them on the same place of the paper as they are located at the same spot vertically, aiming to investigate the dynamic structure of this library. Moreover, combining my previous walking experience, Figure 8 interestingly demonstrates my walking patterns with geometric shape of the garden outside the library in a relation to my walking patterns inside the library. Moreover, on these walking patterns, there are a lot of dots which shows that sometimes I had to stop when I pass by people, tables or other bodies on each floor and outside the learning centre. This could be a metaphor revealing the ideas that the environments, the building, the elements inside the building and me can be an assemblage, and each body affects each other by mutual activities.

\section{VII - After the Encounter}

After this repetitive visiting, suddenly, I realized that I have jumped out of my existing knowledge of material culture studies by living at the moment with the interactions with Irving, K. Barber Learning Centre. More importantly, my embodied experience tells me that:

Material culture is about the everyday; it exists in our mundane lives, not only limited to the past society. Material culture is not isolated; it has connections with the environments and human beings. Material culture is alive; it does have power to affect us and let us have our own visual language.

I have changed due to an in-between space of "getting lost" and "finding meanings". As the French phenomenological philosopher, Maurice Merleau-Ponty (1968) states, each body/subject participates with other bodies/subjects, influencing on each other, and consequently, original bodies/subjects are changing continuously while still keeping their own specificity. 


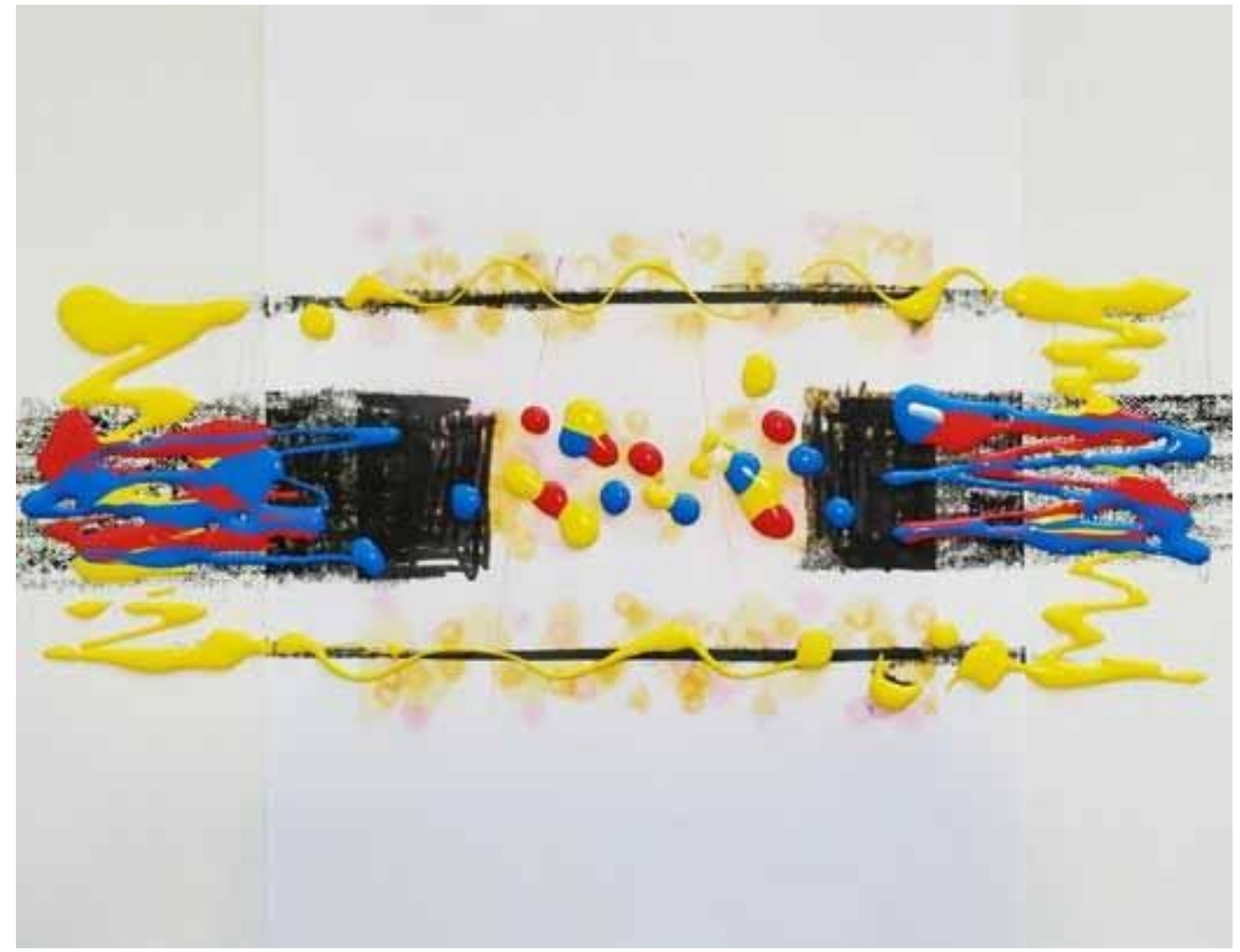

Figure 9 painted by myself illustrates a complex and dynamic relationships between Irving,

K. Barber Learning Centre and me during the break.

Two thin black lines represent the Learning Centre and me with continuous activities, experience and changes separately. In the middle part, the gap represents the time break. However, it would not be a simple break. It contains various events happening without notice. Random and colourful dots and lines are exactly presenting these potentialities. For the Learning Centre and me, we will not stop our lives by this break, but we will experience new things with diverse agencies that could affect us.

Time has passed. From Figure 10, it shows the painting "Break" two weeks after. Moreover, after two weeks, you can see the painting is not only painted by me, but also the pigment itself, the materials and the environment. For Figure 10, it shows the interaction of the pigments and the paper; for Figure 11, it demonstrates the paper has not only changed on the surface horizontally but more importantly the shape vertically as it was gradually being soaked by the pigment. Significantly, the painting has changed multi-dimensionally. Comparatively speaking, I have changed as well, not just "horizontally" but also "vertically", and we should not forget the process of "becoming" of living material culture and ourselves. 


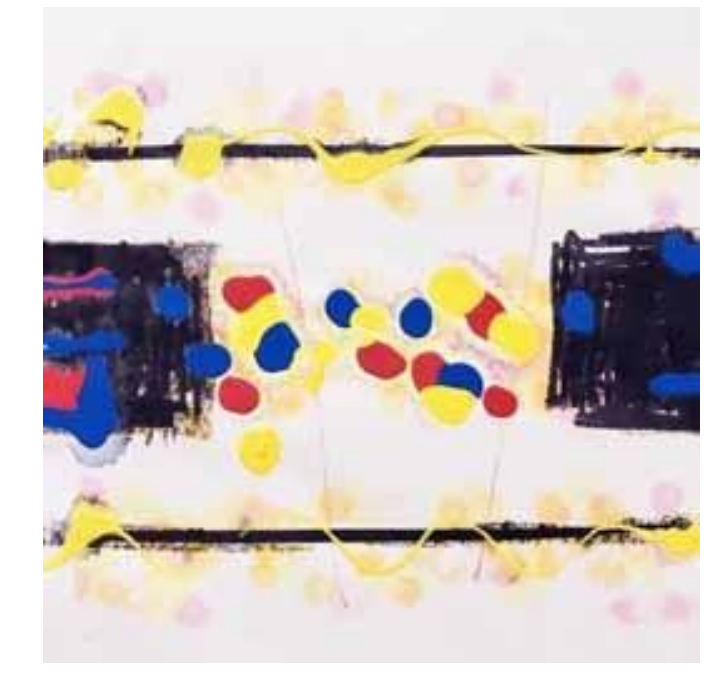

Figure 10- After the encounter 02

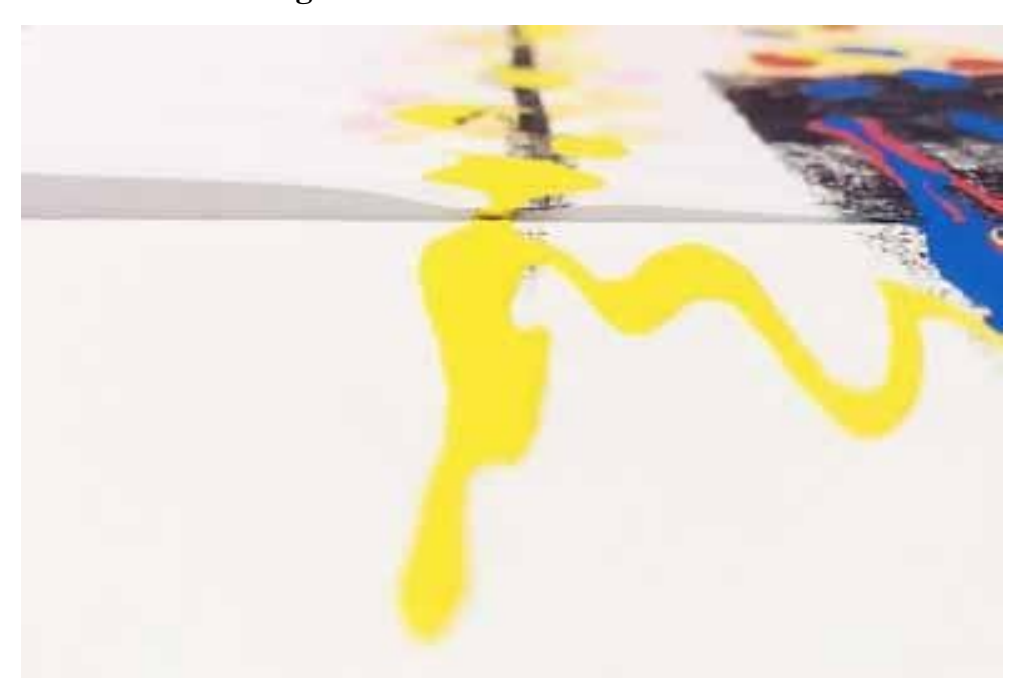

Figure 11- After the encounter 03

\section{Re-Encounter}

After two weeks' break, it is the time to re-encounter with Irving, K. Barber Learning Centre. Significantly, when the re-encounter comes, the familiar unfamiliar and the unfamiliarfamiliar will sequentially come as well, leading a novel experience to create new concepts and understandings.

"I wanted to give the space underneath the table some sort of authority. Casting it in plaster monumentalized a space that is ignored" (Whiteread, 2010, pp.122). 

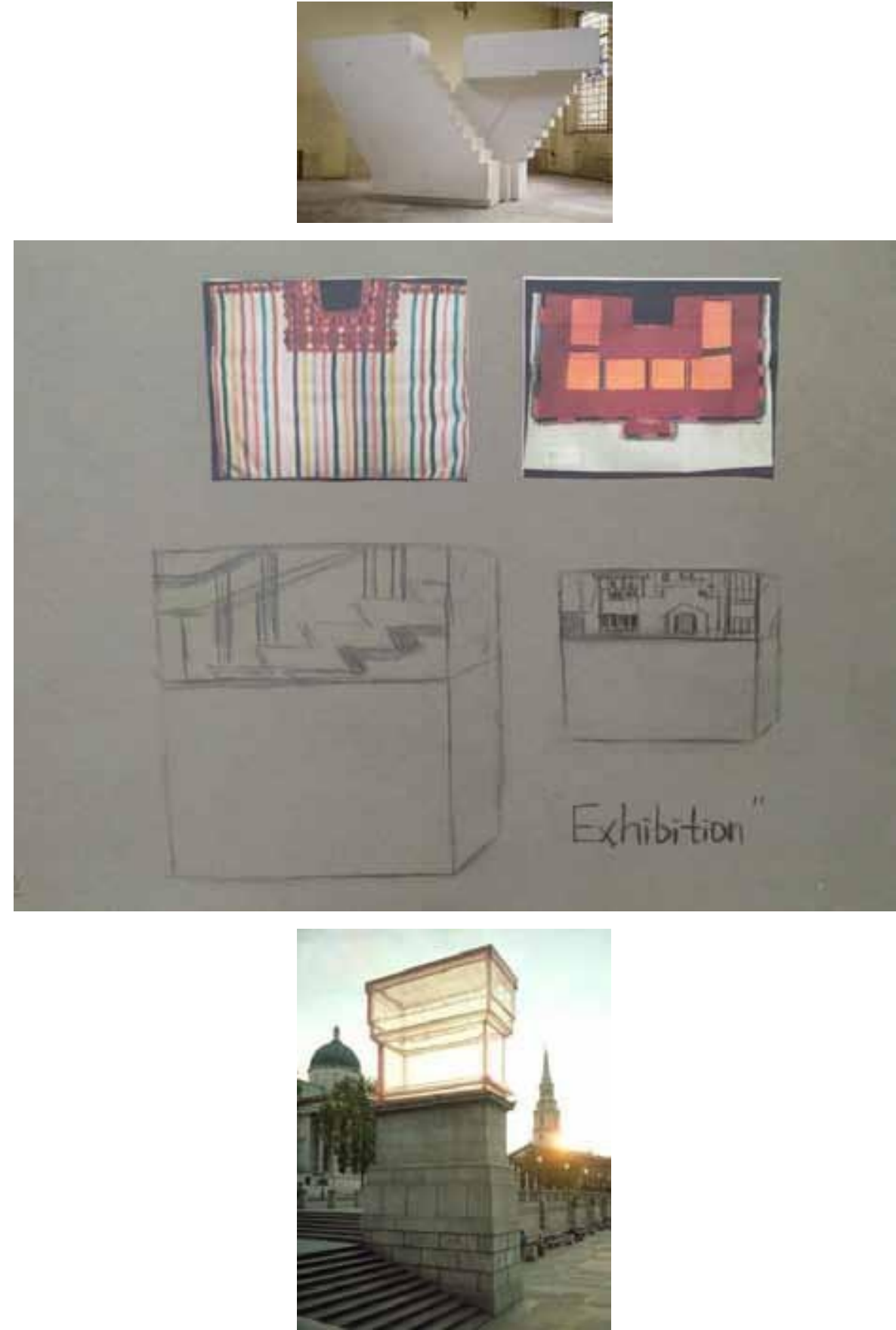

Figure 12- The Exhibition in the learning centre

This "exhibition" on the second floor (Figure 12) somehow reminds me these words said by the British artist, Rachel Whiteread. In most of her artworks, Whiteread try to give authorities to forgotten things, connecting her long-time or every day observing. Take her work Untitled (Stairs) as an example (Figure 13), she sculptured the negative space of stairs, which asks the audience to think about the ignored space. More significantly, it also asks the audience to reconsider the thing they cannot easily see, notice and touch in their mundane lives. Moreover, her work Monument shown in Figure 14 also correspond to this idea that how ignored space can be captured and how to attract the attentions to it from the public. Hence, art could be a 
way to evoke our awareness of the surprising parts of common objects, ignored spaces and our lives. My picture was also trying to record what I saw through the exhibition from the library. It is not just about what we see on the surface which displaying some traditional Mayan costumes from Chiapas, Mexico, but also the ignored context of the library (e.g., the stairs and other the inner structures) and potential "otherness" which "is an entangled relation of difference" (Barad, 2011, p. 150). More importantly, the ignored space could also be a metonymy to students. In art teaching, teachers should not possess a leading power, instead, it is important to consider students' voices which are normally ignored like the space and air. Comparatively speaking, the studies of material culture should not always be anthropocentric as well.

Through the walking experience around/in/with Irving, K. Barber Learning Centre, personal engagement might cause us to forget the focus of our original interest or existing knowledge lens. However, this could be also the meaning of a/r/tography helping us go to somewhere we cannot estimate, somewhere full of potentialities and somewhere let us enjoy the feeling of getting lost and find meanings during our ongoing and living inquiries. Furthermore, the different propositions presented by each figure in this paper, such as "smelling" and "listening", exactly reflects the non-linear processes and potential of otherness. Significantly, these multisensory experiences involve more than the conventional perspectives of material culture studies and push the boundaries of it.

\section{Non-Ending Conclusion}

\section{New Materialism and Art Education}

One of the most important findings is that new materialism updated my understanding of material culture through aesthetic experience simultaneously demonstrating its power to art practice and pedagogical meanings. As Hickey-Moody and Page (2015) say, "bodies, knowledge systems, sociability and matter are co-constructed. ... one ... always embedded in another one". Specifically, human-nonhuman intra-actions and powers are in relation to the mutual entanglement between human and matter which can contribute new knowledge and social identity. Therefore, matter is able to deliver us new ways of being which is meaningful and pedagogical. More significantly, Hickey-Moody and Page (2015) implement this concept to embodied experience of art learning and making to consider the pedagogical nature of matter and convey new ways of pedagogy. Moreover, with an emphasis on materiality, new ways of pedagogy situated human-nonhuman animacy and intra-action experience require us to consider what students and teachers can do with the environments instead of pursuing the answer for what are the various identities that students and teachers may encounter (Hickey- 
Moody \& Page, 2015).

Because, during the affective art learning process, identities will appear and be constructed accompanying with the embodied experience. Based on the question what affective body can do, Rousell et al. (in press) suggest five rules to study under new materialism, including 1) learning by doing rather than learning before doing, 2) exploring the relationship between individuals and the group, 3) observing the impacts of living environments on learning, 4) learning under open instructions, and 5) recording learning experience in a narrative way. Hickey-Moody and Page (2015) also propose four methods, consisting of 1) focusing on the continuous phases that materials and spaces impact on bodies and bodies impact on ideas, 2) concentrating on the relations among students, matter and the environments, 3) encouraging students to share practices with peers and teachers and negotiate new meanings, and 4) invite teachers to think themselves as students to push themselves engaging with more experience critically and creatively. Comparing these two theories, the individualities and commonalities are easy to see. It would be noteworthy to combine them, and consider the issue 1) whether the whole learning process can be regarded as art and which art forms can be occupied and 2) whether it is more valuable to consider the power of human-nonhuman animacy that can create art with astonishment and potentialities.

\section{The Significance}

By applying new materialism, it can greatly enhance my understanding of the relationship among Irving, K. Barber Learning Centre, the environments and me through my walking experience. It also offers me the opportunities to create my own art language and work outside the limitations of self-identity due to human-nonhuman animacy. As Hickey-Moody and Page (2015) indicate, artists also can be material thinkers, which allows them to create new forms and different aspects of knowing, being and the world. More significantly, Rousell et al. (in press) reports that art can be created without human intervention, and we should not always largely rely on human actions. All these outstandingly findings update my thoughts of my project and motivate me for more walking experience. Moreover, through this walking project, multidimensional and multimodal study of material culture emerged. Time, space, environment and even tiny materials are all essential. Relevantly, it is meaningful to think place or other materials as an ongoing process and event (Springgay and Truman, 2018). Therefore, learning by doing with a/r/tography can be a suggestive and significant way for further related material culture studies, and it is important for us to always think about relations among different bodies and open to otherness and potentialities. Finally, I would like to say: 
My work is not linear; It is scatter-dotted, divergent and radiating.

Significantly, it always invites me to keep going on an endless journey to explore new aspects impacted by human-nonhuman entanglements and animacy which exists in every moment and movement during our mundane lives and living material culture.

To be Continued ...

\section{References}

1) Bennett, J. (2010). Vibrant matter: A political ecology of things (Chapter $1 \& 2$, pp. 1-38). Durham: Duke University Press.

2) Barad, K. (2011). Nature's queer performativity. Qui Parle: Critical Humanities and Social Sciences, 19(2), 121-158.

3) Bolin, P. E., \& Blandy, D. (2003). Beyond visual culture: Seven statements of support for material culture studies in art education. Studies in Art Education, 44(3), 246-263.

4) Clark, P. (2011). Introduction. In P. Clark, (Ed.), New possibilities for the past: Shaping history education in Canada (pp. 1-30). Vancouver: UBC Press.

5) Hickey-Moody, A., \& Page, T. (2015). Introduction: Making, matter and pedagogy. In A. Hickey-Moody \& T. Page (Eds.), Arts, pedagogy and cultural resistance: New materialisms (pp. 1-20). Maryland: Rowman \& Littlefield International, Ltd.

6) Irwin, R. L. (2004). A/r/tography: A metonymic métissage. In R. L. Irwin \& A. DeCosson (Eds.), A/r/tography: Rendering self through arts-based living inquiry (pp. 27-38). Vancouver: Pacific Educational Press.

7) Irwin, R. L., Beer, R., Springgay, S., Grauer,K., Gu, X., \& Bickel, B. (2008). The Rhizomatic Relations of A/r/tography. In S. Springgay, R. L. Irwin, C. Leggo, \& P. Gouzouasis (Eds.), Being with A/r/tography (pp. 205-220). Rotterdam: Sense Publishers.

8) Irwin, R. L., \& Springgay, S. (2008). A/r/tography as Practice-Based Research. In S. Springgay, R. L. Irwin, C. Leggo, \& P. Gouzouasis (Eds.), Being with A/r/tography (pp. xix-?). Rotterdam: Sense Publishers.

9) Ingold, T. (2013). Making: Anthropology, archaeology, art and architecture (Chapter 7, pp. 91-108). Oxon: Routledge.

10) Leggo, C. (2008). Autobiography: Researching Our Lives and Living Our Research. In S. Springgay, R. L. Irwin, C. Leggo, \& P. Gouzouasis (Eds.), Being with A/r/tography (pp. 324). Rotterdam: Sense Publishers.

11) LeBlanc, N., Davidson, S. F., Ryu, J., \& Irwin, R. L. (2015). Becoming through a/r/tography, autobiography and stories in motion. The International Journal of Education through Art, 11(3), 355-374. 
12) LeBlanc, N., \& Irwin, R. L. (in press). A/r/tography. In Noblit, George (Ed.), Oxford Encyclopedia of Qualitative Research Methods in Education. New York, NY: Oxford University Press.

13) McCollum, A. (1986). Perfect vehicles. In B. Wallis (Ed.), Damaged goods: Desire and the economy of the object (pp. 6). New York, NY: New Museum of Contemporary Art. Merleau-Ponty, M. (1968). The visible and the invisible (pp. 130-155). Evanston: Northwestern University Press.

14) O’Sullivan, S. (2001). Writing on art (case study: The buddhist puja). Parallax, 7(4), 115121.

15) Pollard, J. (2004). The art of decay and the transformation of substance. In C. Renfrew, C. Gosden \& E. DeMarrais (Eds.), Substance, memory, display: Archaeology and art (pp. 4762). Cambridge: McDonald Institute for Archaeological Research.

16) Rousell, D., Lasczik Cutcher, A., Cook, P., \& Irwin, R. L. (in press). Propositions for an environmental arts pedagogy: A/r/tographic experimentations with movement and materiality. In A. Cutter-MacKenzie, K. Malone, \& E. B. Hacking (Eds.), International research handbook on childhood nature: Assemblages of childhood and nature research. New York: Springer.

17) Steinweg, M. (2011). What is an object. In A. Budak \& P. Pakesch (Eds.), Antje majewski: The world of Gimel. How to make objects talk (pp. 218-220). Berlin \& New York, NY: Sternberg Press.

18) Springgay, S., \& Truman, S. E. (2018). Introduction: walking methodologies in a morethan-human world. In S. Springgay \& S. E. Truman (Eds.), Walking methodologies in a more-than-human world: WalkingLab (pp.1-15). Oxon: Routledge.

19) Tate Modern. (n.d.). Exhibition Guide: Rachel Whiteread. Retrieved November 28, 2018 from: $\quad$ https://www.tate.org.uk/whats-on/tate-britain/exhibition/rachelwhiteread/exhibition-guide

20) VADS. (n.d.). Core record: Monument. Retrieved November 28, 2018 from https://vads.ac.uk/large.php?uid=68226

21) Whiteread, R. (2010). An interview by Michael Archer. In W. Furlong, \& M. Gooding (Eds.), Speaking of art: Four decades of art in conversation (pp. 121-125). London: Phaidon.

Received: February 11, 2018

Accepted: April 23, 2018 